\title{
DESEMPENHO ESCOLAR EM ADOLESCENTES PRATICANTES E NÃO PRATICANTES DE CAPOEIRA
}

\author{
Franklin Bento da Silva ${ }^{1}$ \\ Sinara Moreira de Freitas Santos ${ }^{2}$, \\ Pollyana Freitas Silva Lima ${ }^{3}$, \\ Marcelo Freire Guerra ${ }^{4}$, \\ Valfredo Ribeiro Dórea ${ }^{5}$ \\ Douglas de Assis Teles Santos ${ }^{6}$
}

RESUMO As lutas são consideradas instrumento de relevância física, emocional e intelectual, contribuindo diretamente no desenvolvimento global do aluno. Neste contexto a Capoeira destaca-se nos aspectos psicológicos e cognitivos, desenvolvendo a atenção, percepção, criatividade, persistência, iniciativa, autocontrole e confiança. O desempenho escolar é alvo de discussão entre os pesquisadores da área da educação, inclusive da Educação Física. Não é intenção deste estudo se valer destas discussões e posicionamentos acerca de avaliação e desempenho escolar, desta forma, em um contexto específico entendemos o desempenho escolar como os resultados de médias e frequência das disciplinas cursadas. $\mathrm{O}$ objetivo dessa pesquisa é comparar o desempenho escolar em escolares praticantes e não praticantes de Capoeira. A amostra foi constituída por 24 alunos, com idade entre 14 e 15 anos de ambos os sexos, divididos em três grupos (A, B, C) com oito sujeitos. O grupo A foi composto por crianças que praticavam Capoeira no Serviço de Convivência e Fortalecimento de Vínculos, o grupo B por crianças que praticavam Capoeira em grupo particular e o grupo C foi o grupo controle, ou seja, não praticavam Capoeira. O desempenho escolar foi obtido através das médias globais das notas e frequências às aulas do $1^{\circ} \mathrm{e} 2^{\circ}$ bimestre. As analises de dados foram realizadas através, Software IBM SPSS versão 20.0, sendo efetuado o teste de Shapiro-Wilk para a normalidade dos dados, e para comparação entre os grupos foi realizado uma ANOVA one way. Foi adotado o índice de significância $p<0,05$. Não houve diferença estatisticamente significativa entre os grupos para as médias globais $(p=0,91)$ e para as faltas $(\mathrm{p}=0,54)$. Estudos demonstraram o melhor desempenho escolar em alunos praticantes de

\footnotetext{
${ }^{1}$ Bacharel em Educação Física pela Universidade Federal de Goiás e Mestre de Capoeira no Serviço de Convivência e Fortalecimento de Vínculos Centro de Convivência Social em Jataí, Goiás.

${ }^{2}$ Bacharel em Educação Física pela Universidade Federal de Goiás.

${ }^{3}$ Licenciatura Plena em Ciências Biológicas, Especialização em Morfofisiologia do Exercício, professora no Instituto Franscisco de Assis em Teixeira de Freitas, Bahia.

${ }^{4}$ Licenciatura Plena em Educação Física pela Universidade Federal de Uberlândia, Mestre em Saúde Coletiva pela Universidade Federal de São Paulo, coordenador da pós-graduação em Fisiologia do Exercício e professor Adjunto I da Universidade de Rio Verde.

${ }^{5}$ Licenciatura em Educação Física, Mestre e Doutor em Educação Física pela Universidade de São Paulo, professor Adjunto II e coordenador do curso de Educação Física da Universidade do Estado da Bahia, Campus X, Teixeira de Freitas, Bahia.

${ }^{6}$ Licenciatura Plena em Educação Física, Especialização em Fisiologia do Exercício, Mestre em Educação Física pela Universidade Federal do Triângulo Mineiro, professor Auxiliar da Universidade do Estado da Bahia, Teixeira de Freitas, Bahia.
} 


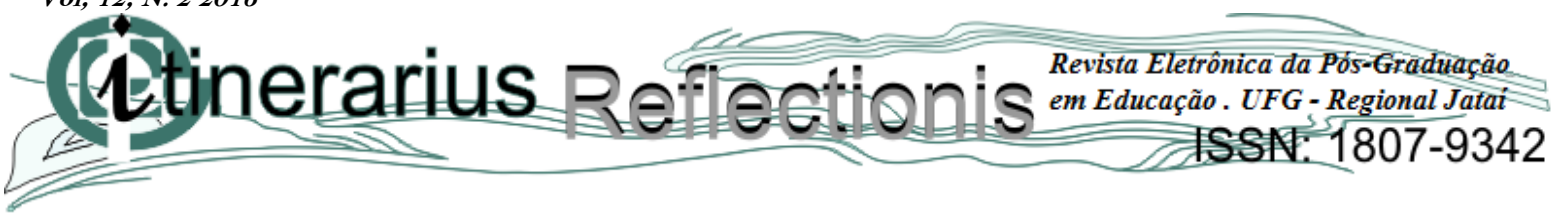

esportes quando comparados aos não praticantes, fato este não comprovado nesta pesquisa, sugerindo aos mestres de Capoeira a repensarem sua práxis, pois esta, é apontada capaz de desenvolver uma série de processos cognitivos, emocionais, afetivos e motores, benefícios estes que poderiam refletir positivamente no desempenho escolar.

Palavras-chave: Capoeira, desempenho escolar, adolescentes.

\title{
COMPARATIVE ANALYSIS OF SCHOOL PERFORMANCE IN ADOLESCENT PRACTITIONERS AND NON PRACTITIONERS OF CAPOEIRA
}

\begin{abstract}
The fights are considered relevant instrument of physical, emotional and intellectual, contributing directly to the overall development of the student. In this context Capoeira stands out in the psychological and cognitive aspects, developing attention, perception, creativity, persistence, initiative, self-control and confidence. The school performance is subject of debate among researchers in the field of education, including physical education. It is not the intention of this study make use of these discussions and statements about assessment and school performance in this way, in a specific context we understand school performance as the results of medium and frequency of courses taken. The objective of this research is to compare school performance in school practitioners and nonpractitioners of Capoeira. The sample consisted of 24 students, aged between 14 and 15 years of both sexes, divided into three groups (A, B, C) with eight subjects. Group A consisted of children who practiced Capoeira in Living Services and Strengthening Linkages, group B by children who practiced Capoeira in particular group and the $\mathrm{C}$ group was the control group, ie not practiced Capoeira. The school performance was achieved through the global average of notes and frequencies of the 1 st and 2 nd quarter. The analysis of data were performed using IBM SPSS software version 20.0, and made the Shapiro-Wilk test for normality of the data, and comparison between groups was performed an ANOVA one way. The significance level $\mathrm{p}$ $<0.05$ was adopted. There was no significant difference between the groups for overall averages $(p=0.91)$ and faults $(p=0.54)$. Studies have shown the best academic performance in practicing sports students compared to non-practitioners, but this has not proven in this study, suggesting the masters of Capoeira to rethink its practice, as this is pointed able to develop a series of cognitive, emotional processes, affective and motor, these benefits that could reflect positively on school performance.
\end{abstract}

Keywords: Capoeira, school performance, adolescent.

\section{Introdução}

Evidencias relatam que a luta faz parte da evolução humana, em relação ao seu contexto histórico, como a luta pela sobrevivência do homem em vários aspectos culturais perante civilização. Segundo Ferreira (2006), na atualidade existe vários sistemas de luta, as 
chamadas artes orientais: Kung Fu, Tai-Chi-Chuan, Karatê, Judô, Jiu-jitsu, Aikido, Tae-Kwon Do, Jet-Kune-Do, Kendo, entre outras. Também existem aquelas consideradas ocidentais como: Boxe, Esgrima, Kick-Boxe, etc. Nos jogos olímpicos modernos, estão presentes algumas modalidades como, Judô, o Tae-Kwon-Do, a Esgrima, o Arco e Flecha, o Boxe, a Luta Livre e a Luta Greco-romana.

A luta passou a ser um instrumento de grande importância física, emocional e intelectual, que contribui diretamente para o desenvolvimento global do aluno. Neste contexto a luta investigada no presente estudo é a Capoeira. Que se destacam aspectos psicológicos e cognitivos, que são capazes de desenvolver; atenção, percepção, criatividade, persistência, capacidade de iniciativa, autocontrole e confiança (LANÇANOVA, 2006).

Capoeira é uma arte marcial brasileira que combina equilíbrio, agilidade e força, e envolve movimentos acrobáticos e de dança, bem como movimentos de salto e aterrisagem, semelhante a ginástica (ARAUJO, COHEN e HAYES, 2015). Entendida hoje, como manifestação cultural, a Capoeira surgiu com os escravos, como uma forma de camuflar treinamentos de lutas através da dança, uma vez que essa prática era proibida por "Senhores" e capatazes (LANÇANOVA, 2006).

Ao longo dos anos, a Capoeira fugiu do estereótipo da marginalização, vista anteriormente como prática de "malandros", hoje possui status de esporte, graças principalmente ao trabalho desenvolvido pelos Mestres, Bimba e Pastinha, e também a legalização efetuada pelo então presidente Getúlio Vargas. Contudo, devemos compreender a Capoeira de uma forma mais ampla, pois devida sua diversidade e riqueza de história ela é entendida como manifestação da cultura corporal, incorporando luta, dança, cultura e tradições (ARAÚJO, COHEN e HAYES, 2015).

Evidências têm sugerido melhor de desempenho escolar em alunos praticantes de alguma modalidade esportiva (BASSANI, TORRI e VAZ, 2003; SETÚBAL, 2010). Contudo a Capoeira em sua ampla manifestação cultural, até o presente momento, não foi investigada sob o prisma de esporte, dança, luta ou qualquer outra identidade com o desempenho escolar.

Hoje a avaliação do desempenho escolar é alvo de discussão entre os estudiosos da área da educação, inclusive por estudiosos específicos da Educação Física (DARIDO e RANGEL, 2011). Não é intenção deste estudo, aprofundar na discussão específica do que seria avaliação e qual a melhor forma de avaliar o desempenho escolar, desta forma, em um contexto específico entendemos o desempenho escolar como o resultado de médias e 
frequência das disciplinas cursadas, assim como nos estudos de Capellini et al. (2004), Carvalho (2005) e Lemes et al. (2003).

A necessidade de explorar a Capoeira, como meio influenciador do desempenho escolar, se justifica por esta ser uma das modalidades mais praticadas no Brasil, por ser verdadeiramente brasileira, pela ausência de estudo similar e pela necessidade de confrontar outros estudos que evidenciaram a influência de outras modalidades esportivas no desempenho escolar, demonstrando a relevância da temática, para professores de Educação Física, Pedagogos, Assistentes Sociais, Mestres de Capoeira, pais e outros agentes da educação, evidenciando a Capoeira como importante ferramenta pedagógica.

Assim surge a hipótese: a pratica da Capoeira influenciaria no desempenho escolar de adolescentes? Nesse contexto o objetivo desse estudo é comparar o desempenho escolar em praticantes e não praticantes de Capoeira, investigando se a média global das notas dos alunos praticantes de Capoeira é maior que a dos não praticantes e averiguar se a média global das faltas dos alunos praticantes de Capoeira é maior que a dos não praticantes. Para tal, nos utilizamos uma consulta através dos boletins escolares, para coleta de dados com a devida permissão dos pais e dos alunos e realizamos procedimentos de estatística descritiva e inferencial, para análise dos dados, caracterizando este estudo como quantitativo.

\section{Fundamentação Teórica}

\subsection{A história da Capoeira}

A Capoeira teve seu início no século XVI durante o período colonial, com os escravos trazidos da África, descobrindo em seus corpos um valoroso aliado pra extravasar seu sentimento de indignação, como forma de expressão corporal. Porém, sua origem, por não haver provas conclusivas acerca do fato, ainda se apresenta de formas divergentes. Inclusive, muitos documentos referentes à época da escravatura foram perdidos, o pouco que existia foi queimado por ordem de Ruy Barbosa, ministro da Fazenda do governo de Deodoro da Fonseca, em 1890, como afirma OLIVEIRA (1989).

Sabe-se, que a Capoeira é a única luta brasileira que utiliza instrumentos musicais. As rodas de Capoeira são ritmadas pelo toque de instrumentos e pelas palmas dos 


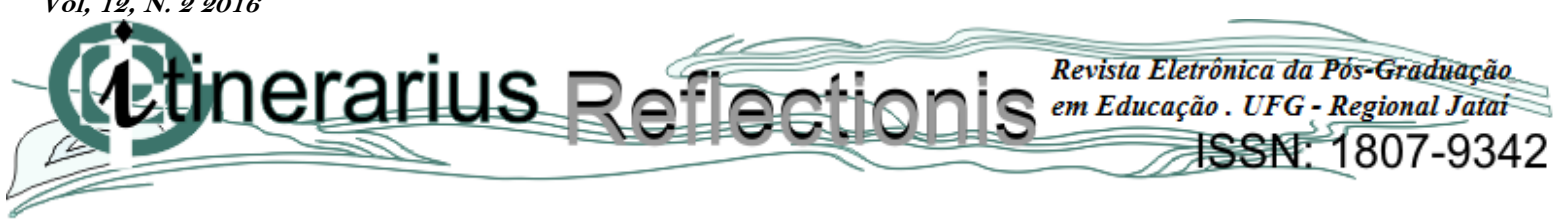

capoeiristas. Rego (1968), o acompanhamento musical da Capoeira, desde os primórdios até nossos dias de hoje, já era feito pelo berimbau, pandeiro, adufe, atabaque, ganzá ou reco-reco, caxixi e agogô. Pastinha (1988) afirma que os instrumentos que compõem o conjunto são: berimbau, pandeiro, reco-reco, agogô, atabaque e chocalho.

Nas rodas de Capoeira o toque do berimbau é considerado fundamental para conduzir o jogo dos capoeiristas. Areias (1983, p. 93) afirma "existem vários tipos de jogos, regidos sempre pelo toque de sua excelência, o berimbau". Como por exemplo, existem diferentes toques de berimbau, e Oliveira (1989, p. 61) esclarece que "alguns sofreram modificações e outros foram inventados por alguns mestres, existindo também uma grande confusão sobre seus nomes de origem".

Capoeira (1998) comenta, em relação aos toques do berimbau, que uns poucos são conhecidos e executados por todos, como o de Angola, São-Bento-Pequeno e São-BentoGrande. O toque de berimbau é também responsável pelo estilo e tipo de jogo que se realiza, o berimbau determina também o ritmo das músicas de Capoeira que compreendem as ladainhas, as quadras e os cantos corridos.

\subsection{A Capoeira como folclore}

Segundo Rego (1968), podemos denominar o processo de legitimação social da Capoeira, porque ela não é mais considerada uma prática de marginais, mas sim valorizar como uma luta e também como uma tradição cultural baiana.

Segundo Rego (1968, p. 361).

Um dos fatores que mais contribuem para descaracterização da Capoeira foi o próprio órgão municipal de turismo da Bahia, com programas de frequentes apresentações a turistas, as academias começam a disputar favores da entidade, acrescentando ingredientes diferentes como, samba de roda, pilhérias etc. A suas apresentações, a fim de torná-las mais agradáveis para o turista. Assim a Capoeira se torna "folclórica". Em vez de se impor como uma manifestação cultural popular, com características próprias, apresenta-se uma imagem adulterada da mesma, procurando o que mais impressione e agrade o turista.

Desta forma, o folclore da Capoeira não se deu através das tradições culturais ou religiosas africanas, mas sim por influência políticas atrativas de atores do governo do estado da Bahia, mistificando algo que na realidade não possui essência dos escravos.

\subsection{A Capoeira como Esporte}


Segundo Almeida (1982), na década de 60, a Bahia continuava sendo o centro da Capoeira. Mas, por essa época, muitos Mestres, atraídos pelas possibilidades econômicas do Sul, começaram a emigrar para o Rio de Janeiro e São Paulo. E aos poucos a Capoeira começava e a espalhava-se pelo Brasil inteiro a fora. Conforme o autor com isso a Capoeira começa então a ganhar popularidade, e a ideia de que ela venha a ser devidamente regulamentada. Assim, a Capoeira poderia ganhar um lugar junto às artes marciais orientais, já aceitas pela sociedade brasileira. Daí então passaria a se chamar de "a arte marcial brasileira", uma luta esportiva com competições regulamentadas.

Surgem, assim na década de 60 os primeiros campeonatos com a tentativa de regulamentar a Capoeira. E, em 1968 e 1969 realizou-se numa base da Força Aérea no Rio de Janeiro o primeiro e o segundo simpósios brasileiros de Capoeira. Nestes, tentou-se "criar uma única nomenclatura" para os golpes, um único sistema de graduação de alunos, critérios para graduação de Mestres, tudo com a intenção de fundar federações de Capoeira e transformá-la em um esporte nacional (CAPOEIRA, 1985).

Naquela mesma época, realizou-se também na Bahia os primeiros campeonatos de Capoeira. Segundo Capoeira (1985, p. 132):

Em 1972 a Capoeira passou há ser considerado esporte pelo Conselho Nacional de
Desportos, e sua prática, como tal, é regulamentada oficialmente, através da
Confederação Brasileira de Pugilismo. Em 1974, é criada a primeira Federação de
Capoeira em São Paulo, e em 1984, a segunda, no Rio de Janeiro. Falta ainda surgir
outra, num terceiro estado, para que se possa criar a Confederação Nacional de
Capoeira, livrando-a da tutela do pugilismo. Em meados da década de 70 realizam-
se também os primeiros campeonatos nacionais de Capoeira.

Essas tentativas de padronizações da Capoeira encontraram diversos opositores, por não concordarem com "amarras" para a sua prática, entendendo que esta deveria ser livre, assim, se fortaleceu ainda mais a divisão da Capoeira em diversos Grupos, com regras próprias e por esse motivo, até os dias atuais, não se tem consenso para uma formalização desta como Esporte (ARAÚJO, COHEN e HAYES, 2015).

\subsection{Desempenho Escolar}

Em um contexto específico, desempenho escolar seria um rendimento através de notas e frequências. Alguns estudos relatam que o professor se perde em uma concepção de que avaliar é apenas atribuir notas, esquecendo de todo contexto educacional. E assim 
deixando de lado papel de memória que é o verdadeiro sentido de aprender. Estudos relatam que o tipo de ensino encontrado nas nossas escolas valoriza a repetição, e se espera em uma única resposta certa, que é geralmente a que está no livro ou na cabeça do professor (WECHESLER, 2002). Esses estudos relatam ainda que a tarefa ou o aprendizado tenha um significado e uma motivação, pois só assim o professor terá prazer em executar ou aprender (TAURINO, 1997; WECHESLER, 2002).

Wechesler, (2002) reafirma a necessidade de gerar o sentimento descrito como "fluir", que pode ser explicado como sentir-se encantado pelo trabalho, ter prazer pela descoberta, inventar pelo gosto de fazê-lo, onde certamente levará a aprendizagem e criatividade. Torna-se um desafio de como trazer a criatividade para a sala de aula, podendo ser demonstrada em qualquer área e não somente pelo meio artístico.

Siqueira (2009) afirma que todos tem potencial criativo, nos mais variados graus de desenvolvimento.

Investigaram o efeito de contar histórias como modo de estimular e desenvolver a criatividade tanto na leitura como na escrita. Tornando se necessário que o professor estimule ao aluno a questionar o que escuta, a propor idéias, indo além da simples informação. Tirando assim o enfoque do ensino tedioso já que tem se o hábito de contar histórias somente na pré-escola e esquecendo-se da importância do mesmo em todos os níveis de aprendizagem (SIQUEIRA, 2009, p. 125).

No estudo de Simões e Carnielli (2002), foi evidenciado que a escola está perdendo sua autonomia e também sua capacidade de educar para a autonomia. $\mathrm{O}$ discurso pedagógico prega a liberdade de expressão e de ensino, mas o que se vê, verdadeiramente, são barreiras das iniciativas e reforços assim beneficiando as repetições castradoras de sonhos e ideais, onde o educando é estimulado para ouvir e responder, não tendo diálogo.

A avaliação do desempenho escolar é objeto de discussão entre os estudiosos da área da educação, inclusive por estudiosos da área da Educação Física, a exemplo de Darido e Rangel (2011). Não é intenção deste estudo se valer dessas discussões e acerca de avaliação e desempenho escolar. Consequentemente, em um contexto específico entenderemos o desempenho escolar como o resultado de médias e frequência das disciplinas cursadas, que são reforçados nos estudos realizados por Capellini et al. (2004), Carvalho (2005) e Lemes et al. (2003). Essa proposta é discutida por Taurino (1997) e entendida como avaliação por critério. 


\section{Procedimentos Metodológicos}

O presente estudo teve como foco investigar o desempenho escolar em escolares de 13 e 14 anos, matriculados e frequentando as aulas no ensino médio e/ou fundamental e possuírem pelo menos seis meses de experiência com a prática da Capoeira. A sua participação foi autorizada pelos pais ou responsáveis, através da assinatura do Termo de Consentimento Livre e Esclarecido. Participaram deste estudo vinte e quatro adolescentes de ambos os gêneros, matriculados em sete escolas publicas da zona urbana do município de Jataí-GO.

O desempenho escolar foi avaliado através das médias globais de notas e frequências referidas ao primeiro e segundo bimestre letivo de 2013, notificadas nos boletins escolares divulgados pelas escolas dos sujeitos pesquisados. A média global das notas foi adotado devido as diferenças de currículos entre as escolas dos sujeitos, minimizando possíveis diferenças. E, na média global das frequências foi contabilizada a quantidade de faltas.

Os participantes foram divididos em três grupos com oito indivíduos. O Grupo A foi composto por indivíduos que praticavam Capoeira oferecida pelo Serviço de Convivência e Fortalecimento de Vinculo de Jataí-Goiás. O Grupo B foi composto por indivíduos que praticavam Capoeira em um grupo local do município de Jataí.

O Grupo C é o grupo controle desta pesquisa, ou seja, não praticavam Capoeira, composto por colegas de sala dos indivíduos do Grupo A. Ambos os grupos entregaram os documentos originais (boletins) expedidos pela instituição de ensino (escolas e/ou colégio) sob à responsabilidade do pesquisador. Após a entrega dos boletins, estes foram analisados e em seguida devolvidos aos respectivos donos.

Para as análises estatísticas foi utilizado o software IBM SPSS versão 20.0. Utilizando-se do teste de Shapiro-Wilk para a normalidade dos dados e para a comparação entre os grupos foi utilizado o teste ANOVA one way, adotando o índice de significância $\mathrm{p}<0,05$. Os dados estão apresentados em média \pm desvio padrão.

\section{Resultados e Discussão}


O resultado da comparação das médias globais das notas é apresentado na Tabela 1. Não constatou diferença significativa entre os grupos $(\mathrm{p}=0,91)$. A prática da Capoeira não alterou o desempenho nas notas dos sujeitos, independentemente de pratica-la no Serviço de Convivência e Fortalecimento de Vínculos (antigo PETI - Programa de Erradicação do Trabalho Infantil) ou em um grupo de Capoeira particular.

Tabela 1 - Comparação da nota, expressa pela média global, entre os grupos.

\begin{tabular}{lllll}
\hline Variável & GA & GB & GC & p \\
\hline Nota & $7,08 \pm 0,87$ & $7,06 \pm 0,81$ & $6,91 \pm 0,65$ & 0,91 \\
\hline
\end{tabular}

A Tabela 2, expressa a comparação das médias globais das faltas entre os grupos estudados, não havendo diferença significativa $(\mathrm{p}=0,54)$ entre os mesmos. Assim a pratica da Capoeira não influenciou na frequência escolar dos capoeiristas.

Os resultados não apresentaram diferença significativa entre os grupos para o desempenho escolar. Por outro lado, estudiosos da Capoeira apontam que esta promove desenvolvimento motor, emocionais, afetivos e cognitivos (AREIAS, 1996; CORDEIRO, 2003).

Tabela 2 - Comparação das faltas, expressa pela média global, entre os grupos.

\begin{tabular}{lllll}
\hline Variável & GA & GB & GC & p \\
\hline Faltas & $19,18 \pm 3,48$ & $16,87 \pm 6,38$ & $18,56 \pm 6,36$ & 0,54 \\
\hline
\end{tabular}

Na presente pesquisa não se investigou aspectos motores, emocionais e afetivos, contudo é possível visualizar uma relação entre o desenvolvimento cognitivo e o desempenho escolar. Neste sentido, os resultados encontrados nesta pesquisa não corroboram com os autores supracitados, pois a pratica da Capoeira não influenciou o desempenho escolar em nenhum dos grupos estudados.

Os resultados sugerem que nos grupos de Capoeira de onde originaram os sujeitos, não há a preocupação de interação entre a Capoeira e o desempenho escolar, ou se 
há, não está sendo efetiva. Assim os mestres dos grupos investigados poderiam rever sua práxis, para que houvesse uma interlocução mais próxima entre a Capoeira e o desempenho escolar. Na tentativa de que fosse implementado por esses mestres artifícios e estratégias compatíveis com os estudos realizados por Wecheler (2002), e Simões e Carnielli (2002) onde os mesmos afirmam que o desempenho escolar é uma variável multifatorial, portanto deve-se atentar para uma gama maior de agentes influenciadores, explorando e absorvendo ao máximo as contribuições positivas para o desenvolvimento.

Apesar dos resultados deste estudo não apresentarem diferença significativa. A Capoeira deve ser entendida como uma prática corporal e cultural que transmite valores e desenvolve mais do que aspectos físicos, conceito este, que deve ser propagado para dentro dos grupos de Capoeira e, sobretudo, aos seus mestres, para que haja uma contribuição efetiva dessa prática no desempenho escolar.

Este estudo apresenta limitações que podem ter influenciado nos resultados tais como: O tempo de prática da Capoeira; as notas e frequências do $1^{\circ}$ e $2^{\circ}$ bimestre que podem não ter sido suficientes para a avaliação do desempenho escolar; e amostra reduzida.

A possível falta de interdisciplinaridade dentro da Capoeira é uma hipótese apontada em relação para a não influência da mesma no desempenho escolar. Essa temática é reforçada nos estudos de Lançanova (2006) reafirmando que as lutas como um todo devem ser exploradas como conteúdos por diversas áreas, do conhecimento cientifico como português, matemática, historia, geografia, literatura, educação física, (dentre outros) etc.

\section{Considerações Finais}

Os resultados encontrados neste estudo demostraram que independentemente de quem praticava ou não a Capoeira, não houve alteração nos resultados de notas e faltas (frequência) dos adolescentes investigados.

Contudo, apesar dos resultados não terem apresentado diferença significativa entre os grupos para o desempenho escolar, outros estudos relatados na literatura evidenciam que a Capoeira promove em seu participante uma série de mudanças nos processos cognitivos, emocionais, afetivos, sobretudo, motores. Nessa direção, os resultados desse estudo, sinalizam aos mestres de Capoeira a necessidade de repensar sua práxis pedagógica, 


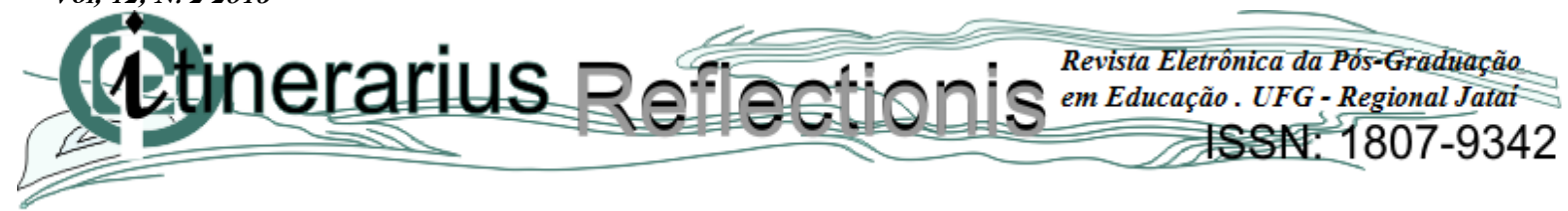

(na tentativa de fomentar) podendo utilizar a interdisciplinaridade como uma ferramenta, indispensável voltado para avaliar o desempenho escolar. Nesse sentido, há a necessidade de novos estudos que investiguem a relação entre o desempenho escolar e a prática de Capoeira, com desenhos metodológicos diferentes.

\section{Referências Bibliográficas}

ALMEIDA, R. C. A. Bimba: perfil do mestre. Centro Editorial e Didático da UFBA Salvador - Bahia -1982.

ARAUJO, S.; COHEN, D.; HAYES, L. Six Weeks of Core Stability Training Improves Landing Kinetics Among Female Capoeira Athletes: A Pilot Study. Journal of Human Kinetics. v.45, n.1, p. 27-37, 2015.

AREIAS, Almir das. O que é capoeira. 2. Ed. São Paulo: Brasiliense, 1996.

AREIAS, A. O que é capoeira. 4. Ed. São Paulo: Ed. da Tribo, 1983.

BASSANI, J. J.; TORRI, D.; VAZ, A. F. Sobre a presença do esporte na escola: paradoxos e ambiguidades. Movimento. v.9, n.2, p. 89-112, 2003.

CAPELlini, S. A.; TONELlOTO, J. M. F.; CIASCA, S. M. Medidas de desempenho escolar: Avaliação formal e opinião de professores. Revista Estudos de Psicologia, Campinas, v. 21, n. 2, p. 79-90, 2004.

CAPOEIRA, N. Capoeira: pequeno manual do jogador. 4. Ed. Rio de Janeiro: Recorde, 1998.

CAPOEIRA, N. Galo já cantou. Rio de Janeiro: Arte Hoje, 1985.

CARVALHO, M. Quem é negro, quem é branco: desempenho escolar e classificação racial de alunos. Revista Brasileira de Educação, São Paulo, v.1, n. 28, p. 77-95, 2005.

CORDEIRO, Y. Reflexões de Alguns Pontos Críticos da Prática da Capoeira na Escola. Disponível em: www.geocities.com/colosseum/field/3170/yara. 02. htm acessado em: 07/04/2003.

DARIDO, S. C.; RANGEL, I. C. A. Educação Física na Escola: Implicações para a pratica pedagógica. $2^{\text {a }}$ Edição, Ed. Guanabara Koogan, 2011.

FERREIRA, H. S. As lutas na educação física escolar. Revista da Educação Física. v.135, n.1, p. 36-44, 2006. 
FRIGÉRIO, A. Capoeira: de arte negra a esporte branco. Revista Brasileira de Ciências Socias. v.4, n.10, 1989.

LANÇANOVA, J. Lutas na educação física escolar: alternativas pedagógicas, 2006. Disponível em: http://lutasescolar.vilabol.uol.com.br/index.html, acessado em: 28/08/2013.

LEMES, S. O.; FISBERG, M.; ROCHA, G. M.; FERRINI, L. G.; MARTINS, G.; ATAKA, M. A. Stress Infantil e Desempenho Escolar - Avaliação de Crianças de $1^{\mathrm{a}}$ a $4^{\mathrm{a}}$ Série, de Uma Escola Publica do Município de São Paulo. Revista Estudos de Psicologia. v. 20, n. 1, p. 514, 2003.

OLIVEIRA, J. L. A capoeira angola na Bahia. Salvador: EGBA; Fundação das Artes, 1989.

PASTINHA, Mestre. Capoeira angola. Salvador: Fundação Cultural do Estado da Bahia. 1988.

REGO, W. Capoeira angola: ensaio sócio-etnográfico. Salvador: Itapuã, 1968.

SIQUEIRA, L. G. G. Motivação para aprendizagem escolar e estilos de pensar e criar. Educação Temática Digital. v.10, n. 1, p. 124-146, 2009.

SETÚBAL, M. A. Equidade e desempenho escolar: é possível alcançar uma educação de qualidade para todos? Revista Brasileira de Estudos Pedagógicos. v.91, n.228, p. 345-366, 2010.

SIMÕES, J. F.; CARNIELLI, B. L. A importância da leitura para o desenvolvimento escolar das aulas do ensino fundamental, Revista de Educação PUC-Campinas. v.1, n. 13, p. 51-63, 2002.

TAURINO, M. S. Norma e critério de desempenho como parâmetros da avaliação da aprendizagem. Estudos em Avaliação Educacional. v. 15, n.1, p. 135-198, 1997.

WECHESLER, S. M. Criatividade de desempenho escolar: uma síntese necessária. Linhas Críticas. v.8, n.15, p. 179-188, 2002. 